\title{
ASPECTOS DA QUESTÃo AGRÁRIA NO BRASIL
}

\author{
Widson Tainan Ros MARTINS ${ }^{1}$ \\ Sedeval NARDOQUE ${ }^{2}$
}

\section{Resumo}

Compreende-se que a gênese dos atuais problemas agrários existentes no Brasil está na forma como a sociedade têm organizado o uso, a posse e a propriedade da terra ao longo de sua história, partindo do pressuposto teórico de que esses problemas são inerentes do próprio desenvolvimento do modo de produção capitalista, que em sua essência é desigual, contraditório e combinado. A proposta de análise desse texto tem como objetivo abordar algumas das principais discussões que permeiam o debate da questão agrária brasileira na contemporaneidade, tanto na perspectiva de sua negação, como na perspectiva de sua afirmação. Para tanto, faz-se leituras e análises de autores consagrados, tais como Martins (1981), Oliveira $(1986 ; 1999 ; 2007 ; 2010)$ e Stedile (2012) e de dados levantados nos censos demográficos (1950 a 2010) e agropecuário (2006) da Fundação Instituto Brasileiro de Geografia e Estatística.

Palavras-chave: Questão agrária, território, capitalismo.

\section{ASPECTS OF THE AGRARIAN QUESTION IN BRAZIL}

\begin{abstract}
It is understood that the genesis of the current agrarian problems in Brazil it is in the way how the society has organized the use, possession and ownership of land throughout its history, starting from the theoretical assumption that these problems are inherent in the own development of the capitalist mode of production, which in its essence is unequal, contradictory and combined. The proposal of analysis of this text aims to approach some of the main discussions that permeate the debate of the Brazilian agrarian question in contemporary times, both in the perspective of their negative and in the perspective of their assertion. For this purpose, they're made readings and analyzes of consecrated authors, such as Martins (1981), Oliveira (1986, 1999, 2007, 2010) and Stedile (2012) and data collected in the demographic censuses (1950 to 2010) and agricultural (2006) of the Fundação Instituto Brasileiro de Geografia e Estatística..
\end{abstract}

Keywords: Agrarian question, territory, capitalism.

\footnotetext{
${ }^{1}$ Mestre em Geografia pelo Programa de Pós-Graduação em Geografia da Universidade Federal de Mato Grosso do Sul - UFMS - CPTL - Três Lagoas - MS. E-mai: martins_tainan10@ hotmail.com.

${ }^{2}$ Docente do Curso de Graduação e de Pós-Graduação em Geografia da Universidade Federal de Mato Grosso do Sul - UFMS - CPTL - Três Lagoas - MS. E-mail: nardoque@ hotmail.com.
} 


\section{ASPECTOS DE LA CUESTIÓN AGRARIA EN EL BRASIL}

\section{Resumen}

Se entiende que la génesis de los actuales problemas agrarios existentes en el Brasil está en la forma como la sociedad tiene organizado el uso, la posee y la propiedad de la tierra al largo de su historia, partiendo del presupuesto teórico de que eses problemas son inherentes del proprio desarrollo del modo de producción capitalista, que en su esencia es desigual, contradictorio y combinado. La propuesta de analice de ese texto tiene como objetivo abordar algunas de las principales discusiones que permean el debate de la cuestión agraria brasileña en la contemporaneidad, tanto en la perspectiva de su negación, como en le perspectiva de su afirmación. Para tanto, se hace lecturas y analices de autores consagrados, tales como Martins (1981), Oliveira $(1986 ; 1999 ; 2007 ; 2010)$ y Stedile (2012) y de datos levantados en los censos demográficos (1950 a 2010) y agropecuario (2006) de la Fundação Instituto Brasileiro de Geografia e Estatística.

Palabras-llave: Cuestión agraria, territorio, capitalismo.

\section{INTRODUÇÃO}

A acentuada concentração fundiária é um dos principais elementos que norteiam o debate da questão agrária no Brasil, gerando inúmeras discussões no plano político e ideológico. Contudo, além da propriedade da terra, existem dois outros elementos que completam a tríade de análise da questão agrária, que são o uso e a posse da terra. Neste sentido, entende-se a questão agrária "[...] como uma área do conhecimento científico que procura estudar, de forma genérica ou em casos específicos, como cada sociedade organiza, ao longo de sua história, o uso, a posse e a propriedade da terra" (STEDILE, 2012, p. 642-3).

Balizada por esse pensamento, a proposta de análise desse texto tem como objetivo abordar alguns dos principais pontos que permeiam o debate da questão agrária brasileira na contemporaneidade, partindo do pressuposto teórico de que o desenvolvimento do capitalismo é desigual, contraditório e combinado (OLIVEIRA, 2007). Para tanto, intenta-se abordar, inicialmente, o caráter contraditório da propriedade da terra na perspectiva do desenvolvimento das relações capitalistas de produção no campo (MARTINS, 1981), pois diferente de outras mercadorias, a terra não é produto do trabalho humano, não possuindo valor em si.

Outra contradição presente no campo brasileiro é a existência de relações não capitalistas de produção, como as relações camponesas. Entretanto, essas relações não 
escapam ao capital, pois possui mecanismos para sujeitar a renda da terra ao seu domínio, combinando as relações capitalistas e não capitalistas de produção sob a lógica de (re)produção ampliada do capital. Para compreender essa sujeição, faz-se necessário recorrer aos conceitos de monopolização do território pelo capital e territorialização do capital, amplamente utilizados por pesquisadores da vertente da Geografia Agrária aportados neste trabalho.

Por último, apresentam-se os diferentes enfoques sobre a Questão Agrária brasileira nas últimas décadas, manifestadas por caminhos antagônicos, um na perspectiva de sua negação, outro na perspectiva de sua afirmação. Nesse sentido, procura-se demonstrar, por meios da análise de alguns dados disponibilizados pelo Instituto Brasileiro de Geografia e Estatística (IBGE), que os argumentos utilizados para a negação da existência de uma questão agrária no Brasil não se sustentam, considerando as inúmeras contradições e problemas existentes no campo cuja origem está na forma como a sociedade brasileira tem organizado o uso, a posse e a propriedade da terra ao longo de sua história.

\section{A CONTRADIÇÃO CAPITALISTA DA PROPRIEDADE PRIVADA DA TERRA}

A expansão das relações capitalistas de produção depende fundamentalmente da separação do trabalhador dos meios de produção. Sem essa separação não existe relação capitalista (MARTINS, 1981, p. 158). Por esse motivo, legitimar e garantir a propriedade privada dos meios de produção, bens e mercadorias é um dos princípios elementares do Estado capitalista. No caso brasileiro, o direito à propriedade é juridicamente assegurado pela Constituição da República Federativa de 1988, compreendido no artigo $5^{\circ}$, inciso XXII.

O marco jurídico de instituição do regime de propriedade capitalista da terra no Brasil remete-se à promulgação da Lei de Terras de 1850, por meio da qual o Estado brasileiro abdicou do domínio da terra, o transferindo para particulares que conseguissem comprovar sua posse por meio de títulos ou aqueles dispostos a comprá-lo, unificando-se posse e domínio numa figura jurídica, a propriedade capitalista da terra. Com a Lei de Terras de 1850, o regime jurídico privou o acesso à maioria dos que nela viviam e trabalhavam. Atualmente, esse cerceamento jurídico do acesso à terra é responsável pela elevada concentração fundiária existente no País, origem e agravante dos mais diversos problemas sociais presentes no campo e na cidade . 
No entender de Stedile (2012), o regime jurídico de propriedade privada tornou a terra uma mercadoria, porém especial, pois, seguindo como referência os estudos de Karl Marx, o autor chama a atenção ao fato de que, ao contrário de outras mercadorias, a terra não é fruto do trabalho humano, mas um bem natural, e que, por não ter valor em si, não é possível classificá-la como uma mercadoria segundo os conceitos da economia política.

A esse respeito, Martins (1981) esclarece:

A apropriação da terra não se dá num processo de trabalho, de exploração do trabalho pelo capital. Portanto, nem a terra tem valor, no sentido de que não é materialização do trabalho humano, nem pode ter a sua apropriação legitimada por um processo igual ao da produção capitalista. A terra é, pois, um instrumento de trabalho qualitativamente diferente dos outros meios de produção. Quando alguém trabalha na terra, não é para produzir a terra, mas para produzir o fruto da terra. $\mathrm{O}$ fruto da terra pode ser produto do trabalho, mas a própria terra não o é (MARTINS, 1981, p. 159-160).

Para Martins (1981), a terra é equivalente de capital, mas não capital. A terra não pode ser confundida com capital justamente por não ser produto do trabalho humano; a terra é um bem natural não reproduzível, que se tornou equivalente de capital ao ser transformada em mercadoria pelos mecanismos do Estado representativo burguês, podendo ser comercializada. Nesse sentido, como a mercadoria que se tornou, podendo ser comprada, vendida ou alugada, a terra adquire preço, e não valor.

Assim sendo, a exploração capitalista da terra depende de uma licença, que pode ser adquiria por meio do pagamento da renda da terra ao seu proprietário. É por esse motivo que Martins (1981) também entende a renda da terra como mais um elemento da questão agrária. A terra concentrada, portanto, não se constitui obstáculo para o desenvolvimento capitalista no Brasil, uma vez que se resolveu à base da aliança terra-capital.

Assim como o capital pode se apropriar do trabalho, também pode se apropriar da terra; pode fazer com que ela, que nem é produto do trabalho nem do capital, apareça dominada por este último. Mas, assim como o capitalista precisa pagar um salário para se apropriar da força do trabalho do trabalhador, também precisa pagar uma renda para se apropriar da terra. Assim como a força de trabalho se transforma em uma mercadoria no capitalismo, também a terra se transforma em uma mercadoria. Assim como o trabalhador cobra um salário para que a sua força de trabalho seja empregada na produção do capital, o 
proprietário da terra cobra uma renda [para] que ela possa ser utilizada pelo capital ou trabalhador (MARTINS, 1981, p. 160).

Nesse sentido, Martins (1981) considera a propriedade capitalista da terra uma contradição antepondo-se a terra ao capital, pois ao pagar pela utilização da terra, o capitalista converte parte do seu capital em renda, paga ao dono da terra, imobilizando improdutivamente essa parte do capital. É com base nessa lógica que, para o autor, o pagamento da renda torna-se uma irracionalidade para o capital.

Contudo, apesar de o proprietário de terras e o capitalista personificarem duas figuras contrapostas, não se pode esquecer que ambos são proprietários privados de instrumentos de produção, e que, em determinados momentos, podem aparecer unidos pelo interesse comum na apropriação da mais-valia produzida pelos trabalhadores (MARTINS, 1981). Isso ocorre, por exemplo, em atividades agrícolas como a soja, a cana-de-açúcar e o milho, commodities exportáveis pois, além de utilizarem os recursos naturais presentes na terra, também se utilizam do trabalho assalariado para realização das atividades inerentes ao seu ciclo de produção.

Também, "[...] ambos podem surgir unificados em uma mesma figura, a do proprietário de terra que também é proprietário de capital” (MARTINS, 1981, p. 166). Quando o capitalista imobiliza capital na compra de terra ele está, na verdade, convertendo capital em renda capitalizada, renda da terra, renda gerada mesmo sem que haja a necessidade da adição de trabalho na terra. Esse processo se dá, pois, diferente do capital, a terra produz renda mesmo sem a adição de trabalho, ou seja, possibilita ao seu dono se apropriar da riqueza socialmente produzida sem trabalhar a/na terra. Essa renda, que resulta do monopólio, é o que Oliveira (2007, p. 43) chama de "renda da terra absoluta".

À medida que aumenta a demanda por alimentos, e, consequentemente, a quantidade de terras disponíveis se torna insuficiente para atender a demanda do consumo, o preço da terra tende a aumentar, elevando, concomitantemente, a renda da terra paga pelo conjunto da sociedade ao proprietário de terra. Neste sentido, Martins (1981, p. 169) considera a propriedade da terra no capitalismo uma relação social, "[...] expressão de um processo que envolve trocas, mediações, contradições, articulações, conflitos, movimento, transformação".

É por esse motivo que a propriedade da terra não deve ser considerada um obstáculo ao desenvolvimento do capitalismo no campo, haja vista que, como lembra Martins (1981, p. 170), ela é apenas uma das contradições inerentes do próprio capitalismo. A propriedade privada da terra, por si só, é suficiente para que o capital se realize, "[...] como mais-valia que 
lhe pertence, todo o excedente produzido no conjunto da sociedade". É o conjunto da sociedade que paga a renda da terra .

Por isso, é muito importante discernir entre produção do capital e reprodução capitalista do capital. A produção do capital nunca é capitalista, nunca é produto de relações capitalistas de produção, baseada pois no capital e no trabalho assalariado. Quando o dinheiro, a riqueza, entra neste último tipo de relação, já não estamos diante da produção capitalista, mas da reprodução capitalista do capital. Só a reprodução é capitalista. Mesmo o crescimento deste capital não é produção, mas reprodução capitalista ampliada (MARTINS, 1981, p. 171).

A produção do capital realiza-se sem necessariamente o uso de relações sociais e de produção tipicamente capitalistas. No Brasil, a produção do capital ocorreu, frequentemente, com a transformação de outros bens naturais e coletivos em mercadoria, por meio, por exemplo, da apropriação capitalista de terras públicas.

\section{MONOPOLIZAÇÃO DO TERRITÓRIO PELO CAPITAL E TERRITORIALIZAÇÃO DOS MONOPÓLIOS: OS MECANISMOS DE SUJEIÇÃO DA RENDA DA TERRA}

A propriedade da terra, como mencionado anteriormente, é uma das contradições do capitalismo, porém, não a única. Outra contradição se faz igualmente presente no Brasil: a existência do campesinato, aqui entendido como classe social, "[...] e não apenas como um setor da economia, uma forma de organização da produção ou um modo de vida" (MARQUES, 2008, p.58). Nessa perspectiva, para Paulino (2008, p. 213), enquanto uma das classes do capitalismo, o campesinato "[...] partilha da condição ambígua de sujeito e objeto dos movimentos contraditórios de produção do território, inscritos pela dinâmica de produção econômica e reprodução social no interior dos conflitos essenciais de classe".

A compreensão teórica da existência do campesinato, como classe social, só é possível levando-se em consideração a coexistência simultânea de mecanismos antagônicos de extração da renda da terra. Isso porque o desenvolvimento das relações capitalistas no campo brasileiro é, em sua essência, desigual e combinado, considerando que, para se reproduzir, o capitalismo cria, recria, e domina relações não capitalistas de produção, igualmente necessárias à sua lógica de desenvolvimento (OLIVEIRA, 1986; 1999; 2007; 2010),

[...] ou seja, ao mesmo tempo em que segue reproduzindo relações especificamente capitalistas mais avançadas, produz também, igual e contraditoriamente, relações não- 
capitalistas de produção e de trabalho, como as relações camponesas de produção, a peonagem etc., todas necessárias à sua lógica de desenvolvimento (OLIVEIRA, 1999, p. 74).

No caso dos camponeses, diferente dos demais trabalhadores, não vendem sua força de trabalho ao capitalista em troca de um salário;

[...] o campesinato é uma classe sui generis, porque mesmo sobrevivendo do próprio trabalho, não o faz do mesmo modo que o operariado. O seu trabalho é um trabalho autônomo, porque realizado no interior do controle dos meios de produção, o que lhe permite escapar à alienação (PAULINO, 2008, p. 217).

Contudo, isso não implica dizer que seu trabalho escapa aos mecanismos de sujeição ao capital. A contraditória reprodução social camponesa no Brasil se realiza justamente no interior dos mecanismos que o capital possui para sujeitá-los ao seu domínio. Essa sujeição não se dá por meio da apropriação formal do trabalho camponês, com a apropriação da maisvalia via trabalho assalariado, mas pela apropriação da renda da terra, realizada plenamente durante a comercialização da produção camponesa.

Para compreensão dos mecanismos de sujeição da renda da terra, nessa perspectiva, é imprescindível recorrer ao conceito de território, apreendido como produção a partir do espaço, cujo sistema territorial é, ao mesmo tempo, produto e meio de produção (RAFFESTIN, 1993). Neste sentido, parte-se da concepção de Oliveira (1999) de território como totalidade concreta, síntese contraditória inerente do próprio processo de desenvolvimento do capitalismo. O território é, portanto, “[...] produto concreto da luta de classes travada pela sociedade no processo de produção de sua existência" (OLIVEIRA, 1999, p. 74).

Dessa forma, são as relações sociais de produção e o processo contínuo/contraditório de desenvolvimento das forças produtivas que dão a configuração histórica específica ao território. Logo o território não é um prius ou a priori, mas a contínua luta da sociedade pela socialização igualmente continua da natureza. O processo de construção do território é simultaneamente construção/destruição/manutenção/transformação. Em síntese, é a unidade dialética, portanto, contraditória, da espacialidade que a sociedade tem e desenvolve (OLIVEIRA, 1999, p. 74).

Todavia, além do conceito de território, se faz igualmente necessária a compreensão de outros dois conceitos elementares, amplamente utilizados por pesquisadores da vertente da 
Geografia Agrária: o de territorialização dos monopólios e o de monopolização do território pelo capital.

A territorialização do capital (ou dos monopólios, como escreve Oliveira (1999)) ocorre quando o capital finca suas bases no território, se instalando no campo e passando, então, a controlar todas as etapas do processo produtivo, se apropriando da renda da terra na produção. Esse processo ocorre nos setores e atividades ligadas ao campo com possibilidades de extração mais elevada da renda da terra, e de uso intensivo das técnicas, possibilitando a menor adição de trabalho nos processos produtivos, mas assalariado.

Contudo, é necessário considerar as atividades do capital no campo, também, se apropriando da mais-valia, mediante a adição do trabalho assalariado durante as etapas do processo produtivo. No caso brasileiro, esse processo ocorre nos setores de ação mais forte do Estado, principalmente no que diz respeito às políticas de crédito agrícola, por meio das quais o destina a maior parte dos seus recursos por meio de financiamentos.

No campo esse processo está igualmente marcado pela industrialização agrícola, ou seja, pelo desenvolvimento da agricultura capitalista que abriu a possibilidade histórica aos proprietários de terra ou aos capitalistas/proprietários de terra para a apropriação da renda capitalista da terra na sua forma diferencial e/ou absoluta. Está marcado, pois, pelo processo de territorialização do capital, sobretudo dos monopólios (OLIVEIRA, 1999, p. 76).

Quanto à monopolização do território, este processo ocorre quando o capital detém o monopólio sobre a circulação das mercadorias provenientes do campo, podendo, em alguns casos, determinar o tipo de produção e como deve se realizar em determinada fração do território, principalmente a camponesa. Neste caso, o capital monopoliza a circulação de mercadorias as quais não é viável à sua territorialização, durante seu processo produtivo, seja por possibilitarem menor extração da renda da terra na produção, como, também, pela necessidade da adição de grande quantidade de trabalho durante o processo produtivo.

[...] Esse processo no campo também está marcado contraditoriamente pela expansão da agricultura camponesa, cujo capital monopolista desenvolveu liames para subordinar/apropriar-se da renda da terra camponesa, transformando-a em capital. Aqui o capital não se territorializa, mas monopoliza o território marcado pela produção camponesa (OLIVEIRA, 1999, p. 76). 
No atual contexto do capitalismo globalizado, no campo, além da sujeição da renda da terra camponesa ao capital durante a circulação, outra forma de sujeição está no consumo, no que se denomina "antes da porteira" (ARRUDA, 2007). Considerando todo o processo de produção, há demanda/consumo, e os processos produtivos agrícolas passaram, a partir da revolução verde, a consumir progressivamente o pacote tecnológico imposto pela "modernização da agricultura", em escala que varia de acordo com a necessidade imposta para cada tipo de cultivo, podendo, então, ser maior ou menor em virtude daquilo que é cultivado e do tamanho da área cultivada em cada unidade de produção.

Segundo Nardoque (2016), a dependência da agricultura à indústria e do campo à cidade se ampliou com esse processo, “[...] pelo crescente consumo de máquinas, implementos, agrotóxicos, sementes melhoradas etc., promovendo a subordinação, principalmente ao capital internacional, representado pelas transnacionais [...]". Nesse contexto, o autor acrescenta que o capital garante a sujeição da renda camponesa de diferentes formas. O capital financeiro por meio de empréstimos bancários, o capital industrial com a venda de insumos agrícolas, e o capital comercial com o monopólio sobre o controle dos mercados. Contudo, isso não significa que todos os camponeses estão expostos a esses mecanismos de sujeição de forma homogênea, ou mesmo que esses mecanismos de sujeição tenham sido suficientes para impedir a reprodução social dessa classe.

\section{A QUESTÃo AGRÁRIA EM QUESTÃO}

Segundo Stedile (2012), se tratando da questão agrária brasileira nas últimas décadas, existem dois enfoques de análises antagônicos. No primeiro, os pesquisadores, orientados pela perspectiva teórica liberal, negam a existência de um problema agrário no Brasil, como por exemplo, a concentração da propriedade da terra. Os argumentos para tal afirmação caminham no sentido de que a existência de latifúndios no país não mais configura entrave para o desenvolvimento do capitalismo no campo, haja vista que, com a modernização da agricultura, as próprias forças capitalistas conseguiram resolver o problema da improdutividade dos latifúndios, que sempre tiveram relação muito estreita com a ideia de terra improdutiva.

Argumentam, também, que as empresas rurais atuantes no Brasil produzem, geram empregos, pagam impostos e, portanto, não há necessidade de se alterar a estrutura fundiária do país. Essa discussão, amplamente difundida pela grande mídia, parte do princípio da não 
existência de demanda por terra por camponeses, haja vista que a maior parte da população do país reside nas cidades, negligenciado, por exemplo, a atuação de movimentos de luta pela terra, como o Movimento dos Trabalhadores Rurais Sem Terra (MST), violentamente reprimido pelas forças conservadoras da sociedade. Os pesquisadores desta perspectiva, conforme aponta Stedile (2012), defendem a maior viabilidade de a terra ficar nas mãos dos capitalistas/latifundiários, mais capacitados para gerirem a terra e os recursos empregados na produção de mercadorias no campo.

Para essa concepção, a concentração da propriedade e seu uso já não representam um problema agrário no Brasil, pois as forças capitalistas resolveram os problemas do aumento da produção agrícola a seu modo, e a agricultura se desenvolve muito bem, do ponto de vista capitalista. Ou seja, a agricultura é uma atividade lucrativa, com aumento permanente da produção e da produtividade agrícolas (STEDILE, 2012, p. 645).

Contrapondo ao primeiro, o segundo enfoque é composto por estudos de pesquisadores orientados pelo pensamento marxista, segundo os quais existem no Brasil diversos problemas agrários e de natureza econômica, social, política e ambiental, resultando diretamente da forma que a sociedade organiza o uso, a posse e a propriedade da terra (STEDILE, 2012). Entretanto, Oliveira (1999) lembra que, mesmo entre os autores desse segundo enfoque, existem divergências quanto à compreensão da existência dos camponeses no país, expressando as diferentes vertentes do pensamento marxista sobre o estudo do campo brasileiro.

A primeira vertente é constituída por autores que defendem que no Brasil houve feudalismo ou relações semifeudais de produção, e, portanto, para que o campo se desenvolvesse, seria preciso superar essas relações com a ampliação do trabalho assalariado . Para os da segunda vertente, cuja concepção está na base da maior parte dos trabalhos de Geografia Agrária, compreende-se que, com o desenvolvimento das relações capitalistas no campo, os camponeses estão fadados ao desaparecimento, pois ao tentarem produzir para o mercado acabariam indo à falência e perdendo suas terras para os bancos, ou mesmo vendendo-as para saldarem suas dívidas, levando-os à proletarização .

No entender de Oliveira (1999), para essas duas vertentes, o campesinato não se constitui como classe social e, portanto, não há lugar histórico para eles na sociedade capitalista avançada. Isso porque os autores que as defendem partem da concepção 
teórica/política da transformação da sociedade capitalista e sua superação pelo socialismo somente por meio da luta entre classes sociais antagônicas: o proletariado e a burguesia.

A terceira vertente, por sua vez, parte da concepção teórica de o processo de desenvolvimento do capitalismo no território brasileiro ser desigual, contraditório e combinado, pois ao mesmo tempo que avançam relações tipicamente capitalistas no campo, também, se reproduzem, igual e contraditoriamente, ralações não capitalistas, como as relações camponesas de produção (OLIVEIRA, 1999, p.73).

Isso quer dizer que, ao mesmo tempo que esse desenvolvimento avança reproduzindo relações especificamente capitalistas (implantando o trabalho assalariado pela presença no campo do bóia-fria), ele (o capitalismo) produz também, igual e contraditoriamente, relações camponesas de produção (pela presença do aumento do trabalho familiar no campo). Entre os mais importantes pensadores dessa corrente estão Rosa Luxemburgo, Teodor Shanin, Samir Amin e Kostas Vergopoulos e, no Brasil, José de Souza Martins, Margarida Maria Moura, José Vicente Tavares da Silva etc. Na geografia agrária, seguindo esta concepção, há os trabalhos de Regina Sader, Iraci Palheta, Rosa Ester Rossini, os meus próprios, e as dissertações e teses de grande parte de nossos orientandos (OLIVEIRA, 1999, p.73).

Diferente das demais vertentes, sem capacidade explicativa, considera-se esta última mais adequada para a análise da realidade do campo brasileiro, e que os argumentos utilizados para a negação da existência de uma questão agrária no Brasil não se sustentam, reconhecendo as inúmeras contradições e problemas existentes no campo cuja origem está na forma como a sociedade brasileira tem organizado o uso, a posse e a propriedade da terra ao longo de sua história.

Quando se analisa os dados disponibilizados pelo IBGE, rapidamente nota-se o equívoco por parte dos pesquisadores da tese da não existência da questão agrária no Brasil. Analisando os dados do Censo Demográfico (2010), verifica-se, aproximadamente, $16 \%$ da população brasileira vivendo no campo, correspondendo a cerca de 30 milhões de pessoas, sendo grande parte delas não proprietárias das terras onde vivem. 
Figura 1 - Brasil: população rural e urbana (1950 - 2010).



Fonte: IBGE - Instituo Brasileiro de geografia e Estatística, Censos demográficos de 1950, 1960, 1970, 1980, 1991, 2000 e 2010.

Atualmente, os aproximados 30 milhões de habitantes do país residentes no campo correspondem a cerca de $90 \%$ da população rural da década de 1950, quando aproximadamente $63,84 \%$ da população vivia no campo. Esses dados evidenciam que, ao contrário daquilo que muitos pesquisadores afirmam em seus estudos, o campo brasileiro não está se esvaziando, mas que a população urbana aumentou significativamente sem que a população rural acompanhasse o mesmo ritmo de crescimento.

Outros dados igualmente relevantes para evidenciar a existência de problemas de natureza agrária no Brasil são os do número de estabelecimentos agropecuários, área, renda e financiamento dos estabelecimentos agropecuários, classificados segundo indicadores da agricultura familiar e não familiar. Apesar do IBGE classificar os dados utilizados segundo indicadores da agricultura familiar e não familiar, entende-se que a agricultura não familiar se constitui por relações tipicamente capitalistas de produção, intimamente ligada ao agronegócio. A agricultura familiar, por sua vez, entende-se basear-se por relações não capitalistas de produção, como por exemplo, a produção camponesa, ideologicamente oculta pelo termo adotado pelo IBGE.

Analisando os dados dos gráficos 1 e 2, verifica-se que, apesar do número de estabelecimentos agropecuários com agricultura familiar corresponderem a 87,9\% do total de estabelecimentos, em 2006, a área ocupada é significativamente menor a dos estabelecimentos 
agropecuários com agricultura não familiar, correspondendo a apenas $32 \%$ da área total dos estabelecimentos agropecuários brasileiros. Apenas com base nesses dados, no Brasil, a concentração fundiária é um dos pilares da Questão Agrária, haja vista que apenas 12,1\% estabelecimentos agropecuários (a maioria ligados ao agronegócio) detém o controle sobre aproximadamente $70 \%$ das terras do país.

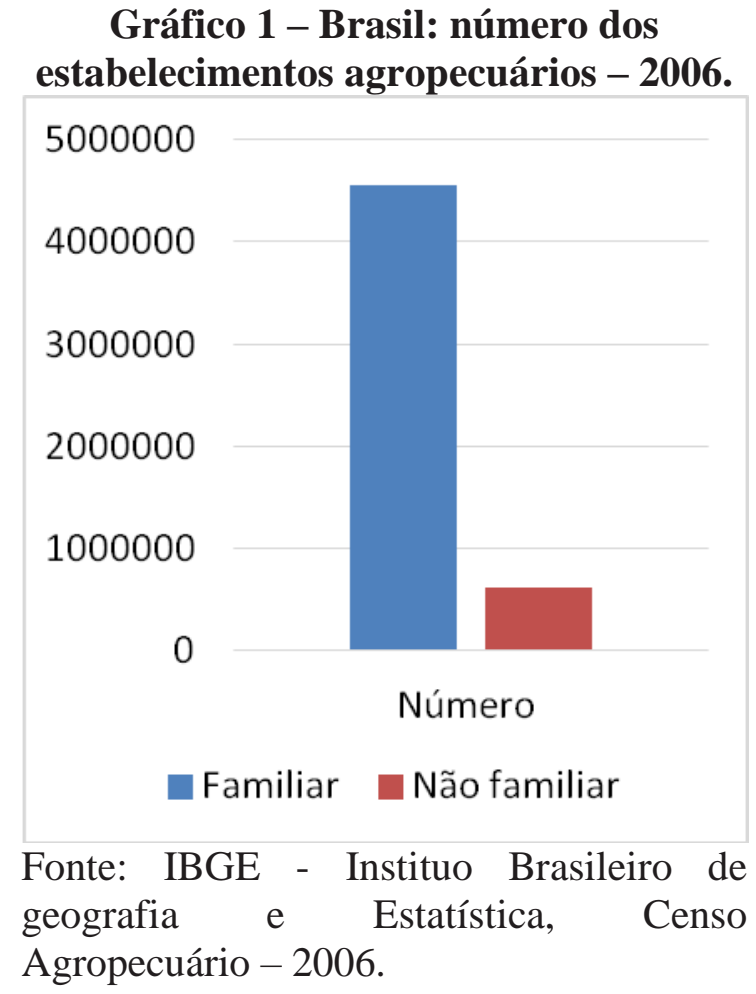

Gráfico 1 - Brasil: número dos

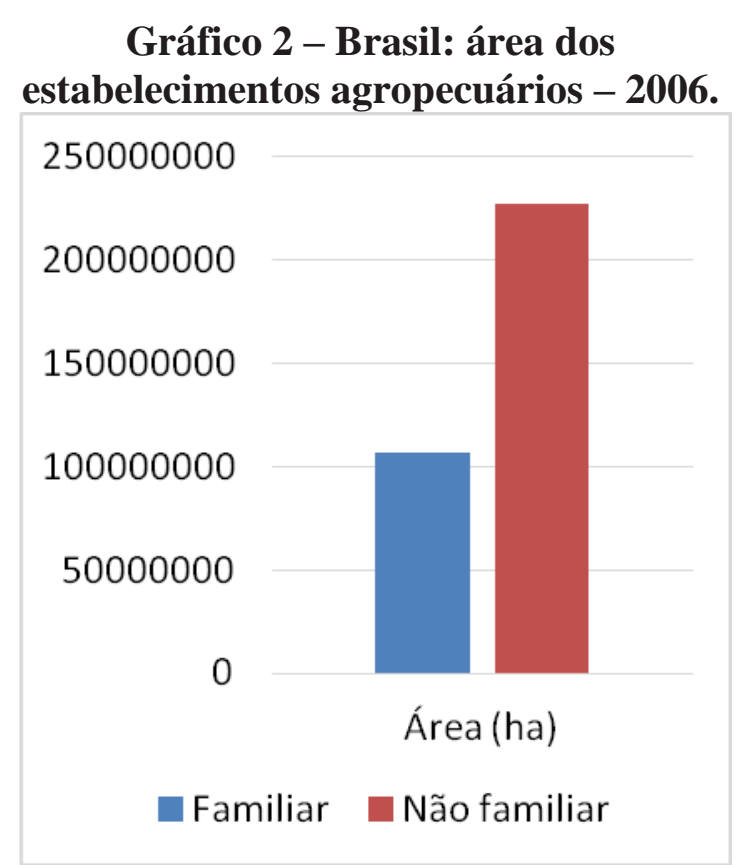

Fonte: IBGE - Instituo Brasileiro de geografia e Estatística, Censo Agropecuário - 2006.

Outro problema de natureza agrária, uma das implicações da concentração fundiária, é a disputa por recursos do Estado via financiamentos. Ao analisar a relação entre os financiamentos agrícolas e o tamanho dos estabelecimentos que os receberam, Oliveira (1999) afirma que a maior parte dos recursos emitidos por meio de financiamentos tem se destinado aos médios e grandes estabelecimentos. Segundo os dados do IBGE (gráfico 3), 71,5\% do valor dos financiamentos agrícolas feitos em 2006 foram destinados aos estabelecimentos agropecuários não familiares, correspondendo a R \$ 15.300.000,00 (Quinze bilhões e trezentos milhões de reais). Contudo, apesar de ter recebido menos de $30 \%$ do valor dos financiamentos e ocuparem apenas $32 \%$ da área total dos estabelecimentos, conforme se verifica no gráfico 4, a renda total dos estabelecimentos com agricultura familiar é apenas 12,6\% menor que a renda dos estabelecimentos com agricultura não familiar. 


\section{Gráfico 1 - Brasil: financiamentos dos estabelecimentos agropecuários - 2006.}

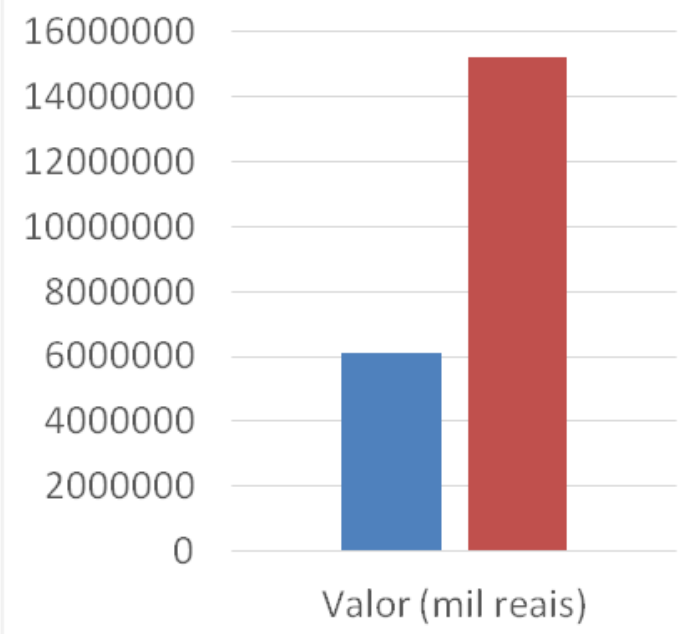

Familiar $\quad$ Não familiar

Fonte: IBGE - Instituo Brasileiro de geografia e Estatística, Censo Agropecuário - 2006.

\section{Gráfico 2 - Brasil - Renda total dos estabelecimentos - 2006.}

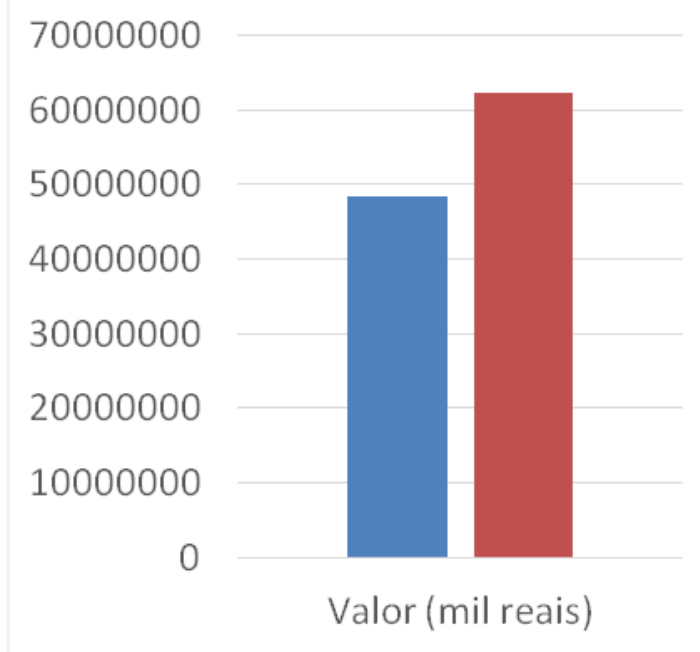

Familiar $\square$ Não familiar

Fonte: IBGE - Instituo Brasileiro de geografia e Estatística, Censo Agropecuário - 2006.

Devido ao fato do desenvolvimento do capitalismo ser desigual, os dados apresentados nos gráficos 1,2,3 e 4 não representam manifestações homogêneas, iguais em todas as frações do território brasileiro. Nesse sentido, quando analisam-se esses dados a níveis de Grandes Regiões ou mesmo por Unidades da Federação, verificam-se profundas desigualdades territoriais, haja vista que, como adverte Goldenstein e Seabra (1982), o desenvolvimento das atividades econômicas no capitalismo pressupõe a existência de formas avançadas de divisão social e territorial do trabalho, resultado de determinações que interferem diretamente no processo de acumulação, ora por aspectos especificamente técnicos, ora por aspectos especificamente econômicos ou político-econômicos.

Esses dados comprovam o quanto a agricultura familiar camponesa é eficiente comparada à agricultura não familiar; ou melhor, os dados certificam o quanto a agricultura camponesa é mais eficiente que o agronegócio, pois levando em conta as condições de produção que esse último possui em relação a ela - ocupa mais da metade da área das terras dos estabelecimentos agropecuários do país e drena a maior parte dos recursos do Estado por meio de financiamentos - a diferença de renda gerada, apesar de ser maior, se torna insignificante. Sobre a eficiência da agricultura familiar camponesa, Mitidiero Junior et al. 
(2017, p. 14) apontam que o Censo Agropecuário 2006 "revelou que os pequenos produtores produzem boa parte dos alimentos que chegam à mesa dos brasileiros", sendo responsável por $70 \%$ dos alimentos consumidos no Brasil.

Stedile (2012) também alerta para problemas como: a concentração da produção, pois segundo o autor, apenas $8 \%$ dos estabelecimentos produzem mais de $80 \%$ das commodities agrícolas; a distorção do uso da terra, pois $80 \%$ delas são utilizadas apenas para produzir soja, milho, cana-de-açúcar, e na pecuária extensiva; a desigualdade social no meio rural gerada por essa estrutura econômica, pois 7 milhões de pessoas ainda vivem na pobreza absoluta, privadas do acesso à saúde e educação.

Esse modelo irracional de agricultura não é autônomo, pois só se sustenta com a intervenção do Estado, atuando diretamente em sua manutenção ao transferir grande parte de seus recursos, via financiamentos, beneficiando assim setores do agronegócio, como o capital ligado às empresas nacionais e multinacionais, os latifundiários e os bancos. Em detrimento dos interesses coletivos da sociedade, o Estado atua na manutenção dos interesses de uma classe que, no entender de Paulino (2008, p. 226), “[...] transformou-se em sócia marginal dos negócios das multinacionais".

O motivo da violenta disputa pelo controle do Estado no Brasil é, em sua essência, uma disputa de classes. Sendo assim, “[...] a dominação consubstancia-se pela preponderância da classe economicamente e politicamente dirigente, via Estado, em duas frentes, sendo pela manutenção da ordem, por meio da imposição e da coerção, mas, também, pelas ideias dominantes" (NARDOQUE, 2017, p.245). A Questão Agrária, portanto, é uma questão de classe.

\section{CONSIDERAÇÕES FINAIS}

Contraditoriamente à perspectiva teórica que nega a existência da questão agrária no Brasil, assiste-se no campo brasileiro inúmeros problemas cuja gênese está na forma como a sociedade têm organizado o uso, a posse e a propriedade da terra ao longo de sua história. Esses problemas são inerentes ao próprio desenvolvimento do modo de produção capitalista, teoricamente compreendido como sendo desigual, contraditório e combinado.

O cerceamento jurídico da propriedade da terra e sua transformação em mercadoria, por exemplo, além de ser uma contradição na perspectiva do desenvolvimento das relações capitalistas de produção no campo, também é responsável pela acentuada concentração 
fundiária existente no país. A concentração da propriedade da terra e a atuação do Estado, que por sua vez a legitima, produzem e perpetuam os inúmeros problemas sociais existentes no campo brasileiro, além de gerar inúmeras distorções quanto ao uso da terra, pois sustentam um modelo de agricultura ineficiente, dependente, caro aos cofres públicos e atrasado do ponto de vista da racionalidade, que é o Agronegócio.

Também é importante considerar que, nos meandros das contradições do modo de produção capitalista, existem cerca de 30 milhões de brasileiros que ainda moram no campo, e a maior parte deles não é proprietária das terras onde vive. No entanto, apesar da dificuldade de acesso à terra e ao crédito e de todos os problemas enfrentados cotidianamente para nela permanecer, esses agricultores familiares camponeses resistem aos mecanismos de sujeição ao capital, pois produzem a maior parte dos alimentos consumidos pelos brasileiros sob uma lógica distinta do modelo capitalista de agricultura.

\section{REFERÊNCIAS}

ALMEIDA, Rosemeire Aparecida; PAULINO, Eliane Tomiasi. Fundamentos teóricos para o entendimento da questão agrária: breves considerações. GEOGRAFIA (Londrina), v. 9, n. 2, p. 113-127, 2000.

ARRUDA, Zuleika Alves de. Onde está o agro desse negócio?: transformações socioespaciais em Mato Grosso decorrentes do agronegócio. Tese (doutorado) - Universidade Estadual de Campinas, Instituto de Geociências. Campinas, 2007.

BRASIL, Casa Civil. Constituição da República Federativa do Brasil de 1988. Presidência da República, Brasília, $1988 . \quad$ Disponível em: <http://www.planalto.gov.br/ccivil_03/constituicao/constituicaocompilado.htm〉. Acesso em: 15 fev. 2018.

GOLDENSTEIN, Léa; SEABRA, Manoel. Divisão territorial do trabalho e nova regionalização. Revista do Departamento de Geografia, USP, n.2, 1982.

HAESBAERT, Rogério. Território e multiterritorialidade: um debate. GEOgraphia, ano IX, n. 17, p. 19-45, 2007.

MARQUES, Marta Inez Medeiros. A atualidade do uso do conceito de camponês. Revista NERA. Presidente Prudente, Ano 11, n. 12, p. 57-67, 2008.

MARTINS, José de Souza. Os camponeses e a política no Brasil. Petrópolis: vozes, p. 61, 1981.

MITIDIERO JUNIOR, Marco Antonio; BARBOSA, Humberto Junior Neves; DE SÁ, Thiago Hérick. Quem produz comida para os brasileiros? 10 anos do Censo Agropecuário 2006. Revista Pegada. Vol. 18 n. 3. Setembro-Dezembro/2017. 
NARDOQUE, Sedeval. A relação campo-cidade: abordagem sob o prisma da questão agrária. IN: SPÓSITO, Eliseu Savério (et. al.). A diversidade da Geografia brasileira: escalas e dimensões da análise e da ação. Rio de Janeiro: Consequência, 2016.

A expansão geográfica do capital e reforma agrária em Mato Grosso do Sul no governos FHC e Lula. In: CAMACHO, Rodrigo Simão; COELHO, Fabiano. (Org.). O campo no Brasil contemporâneo: do governo FHC aos governos petistas (questão agrária e reforma agrária ? vol. I). 1ed.Curitiba - PR: CRV, 2017, v. 1, p. 243-272.

OLIVEIRA, Ariovaldo Umbelino de. A apropriação da renda da terra pelo capital na citricultura paulista. Terra Livre, ano 1, n.1, p. 26-38, 1986.

A geografia agrária e as transformações territoriais recentes no campo brasileiro. In. Novos caminhos da geografia. São Paulo: Contexto, 1999, p. 63-110.

Modo de produção capitalista, agricultura e reforma agrária. São Paulo: Labur Edições, 2007.

Agricultura e indústria no Brasil. Campo-Território: Revista de Geografia Agrária, v. 5, n. $10,2010$.

PAULINO, Eliane Tomiasi. Territórios em disputa e agricultura. In: FABRINI, João Edimilson; PAULINO, Eliane Tomiasi (org.). Campesinato e territórios em disputa. São Paulo: Expressão Popular, 2008.

SAQUET, Marcos Aurelio. As diferentes abordagens do território e a apreensão do movimento e da (i) materialidade. Geosul, v. 22, n. 43, p. 55-76, 2007.

STEDILE, João Pedro. Questão agrária. In: CALDART, CALDART, Roseli Salete (et.al). Dicionário da educação do campo. São Paulo: Expressão Popular, 2012.

\section{Recebido em Março de 2018}

Aprovado em Junho de 2018

Publicado em Julho de 2018 